\title{
Developing an Android-Based Game for Chemistry Learners and its Usability Assessment
}

\author{
https://doi.org/10.3991/ijim.v14i15.14351 \\ Muhammad Nazar $\left.{ }^{\bowtie}\right)$, Rusman, Isfin Cahyani Putri, Kana Puspita \\ Universitas Syiah Kuala, Banda Aceh, Indonesia \\ mnazar@unsyiah.ac.id
}

\begin{abstract}
Nowadays, smartphones are not only used for communication purposes but also for gaming and studying. Gaming is trendy among adolescents in daily activity. The gamification of chemistry concepts, therefore, becomes very interesting and promising to enhance students' intention of learning and promoting ICT literacy among university students. In this article, we reported the development of an Android-based game on the concept of colloids. Volunteered students $(\mathrm{N}=100)$ from the Faculty of Education and Teacher Training took part in the implementation phase. Need assessment suggested that the concept colloids should be a specific topic to be developed as chosen by a significant number of respondents. The validity of the app in terms of the instructional design, software design, and the visual aspects scored above average (between 90 and 99\%). The developed app was found to be very easy to use, practical, and straightforward, with an overall usability score of $85.1 \%$.
\end{abstract}

Keywords - Android game, colloids, chemistry, learning media.

\section{Introduction}

\subsection{Learning media integration}

The use of instructional media in learning has increased significantly in the last decade [1]. In the past, teachers relied only on conventional learning media such as blackboards and textbooks. Whereas digital media growing very fast [2], nowadays, integrating ICT and computer software to the learning process has become very popular among educators [3]. Besides, the rapid growth of both smartphone devices and its software offers numerous apps for students for independent learning. In this digital era, students have a great chance to get involved more intensely in online or computer-based educational apps, sometimes without the teacher's guidance. Therefore, integrating digital content into learning activities become crucial and essential [4].

However, educators all over the world and especially in Indonesia as a developing country, encounter some difficulties in engaging students in the classroom using computers or smartphones. Firstly, the internet infrastructure is the main reason for the teacher to be able to attract students to use ICT. Adequate internet access would help 
teachers introducing technological based learning for the students. It will not be a problem for some schools in big cities like Jakarta, Bandung, and Surabaya, where internet infrastructure has settled. However, according to the annual report of Ministry of Education and Culture [5], there are more than 13000 public and private Senior High Schools all over Indonesia that most of them located in the suburb area having no adequate access to the internet. Secondly, the teachers are also struggling in developing proper learning media and mobile applications for their students due to a lack of development skills [6], [7]. Alternatively, teachers will usually download paid or free apps from the app market or app store. However, not all available apps on the market best fit some specific subjects like chemistry, physics, and mathematics. Lastly, another problem encountered by teachers is school regulation for students. Almost all high schools and secondary schools in Indonesia are prohibiting students from using smartphones in the school area [8], limiting students' interaction with electronic devices specially the smartphone due to concern of its use abusing.

In contrast, some private schools have been adopting quite promising solutions to integrating gadgets in learning activities by associating the tablet use to the schools' curricula. By controlling students' activities, the process of integrating technology into the classroom would give several benefits, including information and technological literacy enhancement[9]-[10], and independent learning skills improvement [11]. Considering that more youngsters are now intensively used smartphones beyond school time but for social media purposes, they also must be allowed to interact with smartphones for educational intention during school. Therefore, the best way to integrating mobile apps to the classroom is by associating the proper app for specific subject matters in the schools' curriculum so students would be more motivated and engaged in learning [12].

Even though some teachers might disagree with the use of the tablet in classrooms, many research findings indicated a positive effect on both students' learning outcomes[13] and engagement. [14] reported that from a total of 23 studies about the utilization of tablets in learning, more than half (16) studies had shown positive learning outcomes. [15], [16], for example, reported successful implementations and reviews regarding the use of smartphone engaged learning in the topics of science. Therefore, not surprisingly, in a developed country like Australia, The New South Wales government encouraged schools and college to integrate tablet use in the classrooms by designing the curriculum [17].

\subsection{Educational games}

Play is a voluntary activity accompanied by feelings, joy, and consciousness [18]. Play always coherent with the necessary capabilities of human beings to express their minds, thought, and ideas by doing certain activities that encourage brain activity. Play is a human beings' favorite way of learning, and it has a significant impact on skills, cognitive, and social. Although designing a good game for education is somewhat tricky, complicated, and time-consuming, but good games could help the teacher reach the students' learning outcomes in short [19].

Educational games have always been practical to attract people of any age [20]. They are also very reliable to engage students in the classroom. Playing games have always 
associated with enhanced learning in student-centered based pedagogy. The games also encourage students collaborations [21], competencies, and skills [20], [22], and develop creative thinking skills. Games are practically useful as pedagogical tools because not only they can enliven teaching topics, but also very useful for dealing with problemsolving and core concepts.

Integrating games in learning activities are not something new; some previous studies reported the development and implementation of gaming into learning activities. For example, [23] developed an Android game for learning colloids, Atiek et al. [24] developed "chemtective" to learn chemistry through detective-problem solving. Wardani et al. [25] have also developed a chemistry board game called the alchemist board, which aimed at enhancing students' learning outcomes and critical thinking ability. [26] have successfully implemented social media and multimedia in learning to elevate students' creativity. Furthermore, we also have previously developed an augmented reality app for learning the concept of molecular geometry [27].

In this study, we developed a picture guessing game on the topic of colloids run on the Android system. The game allowed the users to guess the displayed pictures by taping the given characters below the image. The game has 30 levels. The level of the game determines the question difficulty meaning higher levels consist of more difficult questions.

\section{Research Method}

\subsection{Development model}

The app was developed based on (R\&D) research method with the ADDIE model. The ADDIE model consisted of 5 fundamental stages, including analysis, design, development, implementation, and evaluation. At the analysis stage, we used seven questions regarding the need analysis of the app.

\subsection{Usability test}

The usability test was conducted to measure the ease of the app as an Android system app. The SUS was initially developed by Brooke [28] in 1996 to evaluate the system usability of a product or service consisted of ten questions based on a Likert scaling rule [29].

\subsection{Validation of game contents and design}

Before the implementation, the app was validated twice to ensure the content validity and design usability of the app. The validation is required to avoid concept misunderstanding among students, so the result of the research can be academically accepted. There were three aspects examined, including software design ( 7 indicators), visual communication (9 quality indicators), and instructional design (5 quality indicators). 


\section{$3 \quad$ Results and Discussions}

\subsection{Need analysis}

Need assessment was conducted to acquire responses from students regarding smartphone usage in their daily activity; the study also aimed to reveal the attitude of students in using mobile applications in learning activities. The result of need analysis can guide the researcher in deciding the right app to develop based on users' experiences and preferences.

Question 1. How long do you use a smartphone everyday?

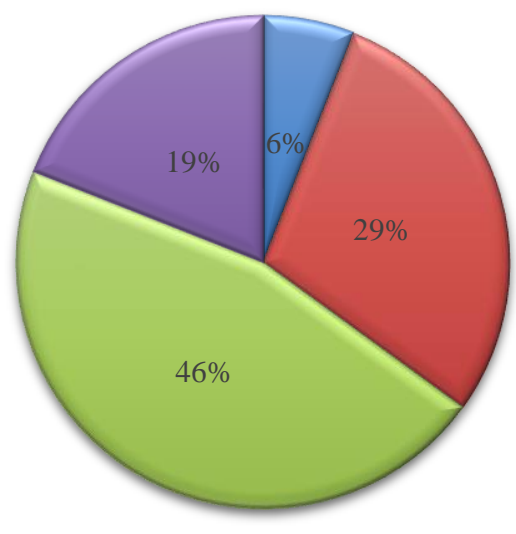

$\square$ 1-5 hours $\square 6$-10 hours $\square$ 11-15 hours $\square 16-20$ hours

Fig. 1. Daily time allocation for smartphone use

Fig. 1. Shows that the vast majority of students used their smartphone for between 11 and 15 hours. While $19 \%$ of the respondents allocated over 15 hours using the smartphone, only $6 \%$ of students spend less than 5 hours a day. This data indicates the intensive interaction between students and the smartphone. [30] reported that most students allocated more than 8 hours a day using their smartphone either for educational or social media purposes. The second question aimed to emphasize students' behavior of using smartphones for game and chemistry learning. 


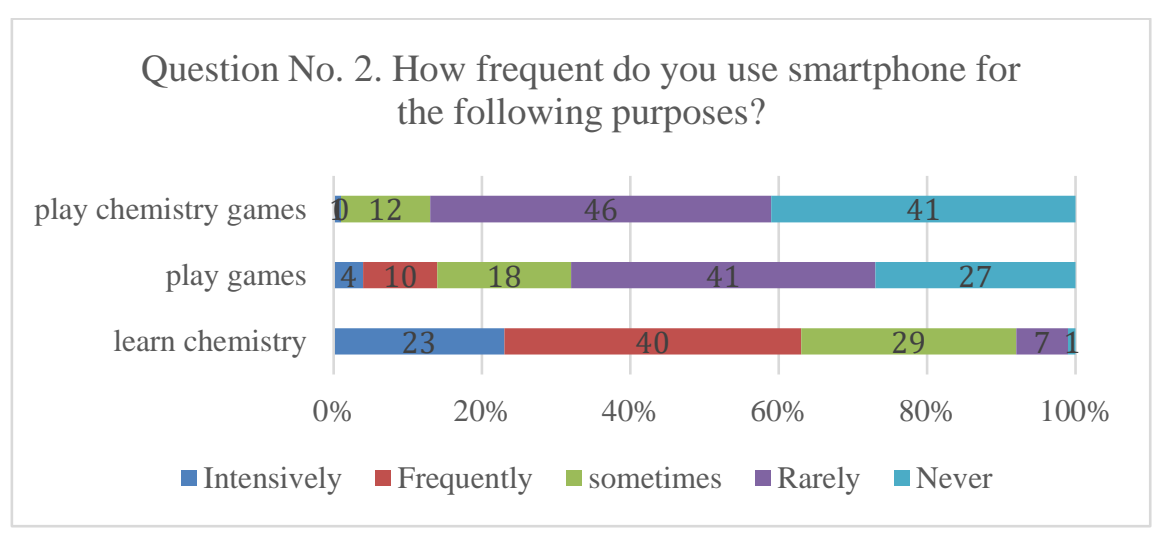

Fig. 2. Smartphone usage frequency for specific purposes

Fig. 2 depicted the attitude of students toward smartphone usage for chemistry-related games. Only $23 \%$ of students intensively using their smartphones for chemistry learning purposes, while the majority of them are frequently utilized smartphones for learning chemistry. In terms of gaming, most of the students rarely played games or chemistry games. Only $12 \%$ of students sometimes played chemistry educational games, and $18 \%$ of students play games using their smartphones. Since most of the students did not involve in using chemistry-related games or apps, we were curious to know students' opinions about the chemistry-related game or app availability on google play or Appstore.

Question No. 3. In your opinion, how many chemistry apps available in appstore or google

play?

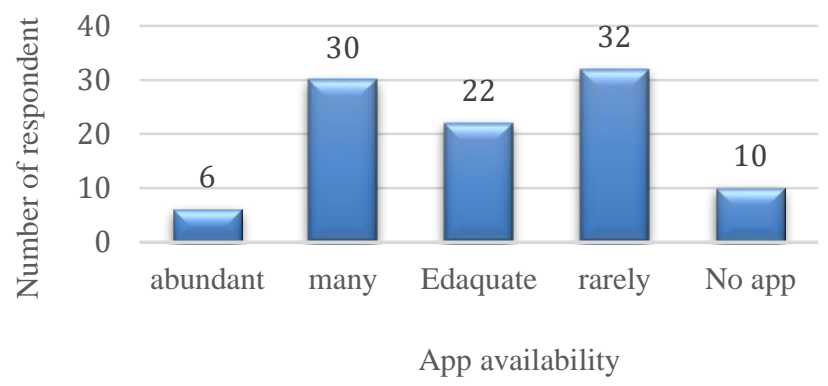

Fig. 3. Students'views toward chemistry app availability

Fig. 3 shows students' opinions toward chemistry-related app available on google play. From a hundred students, 32 of them argue that there are not so many apps available for learning chemistry, while most students still think of many apps available in the app market. This answer aligned with the previous question regarding students' ex- 
periences in using chemistry applications, whether to learn chemistry or play the chemistry-related game. Almost half of the total students (41\%) have never played a chemistry game app on their smartphones.

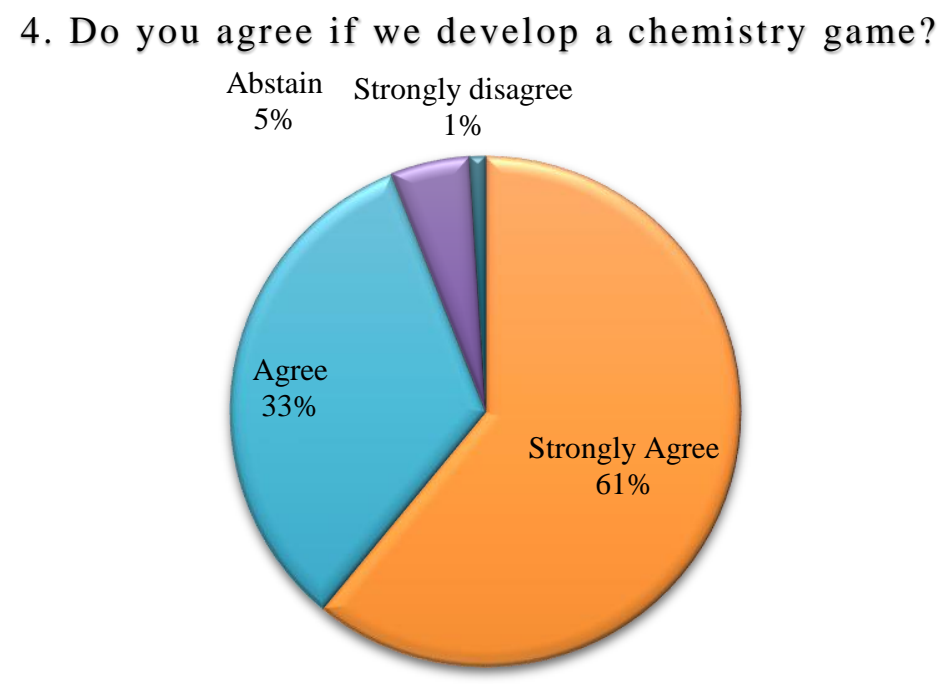

Fig. 4. Students' opinions regarding app development

We saw the great interest of students in the chemistry game app development since most of the students responded positively to the development plan of the chemistry app, as depicted by fig. 4. Students prefer a fun and joyful way of learning the serious matter like chemistry and physics, according to [31], joyful learning promotes fun, enthusiasm, and positive cognitive experience in the classroom. 
Question No. 5 Which concepts should be chemistry game developed for?

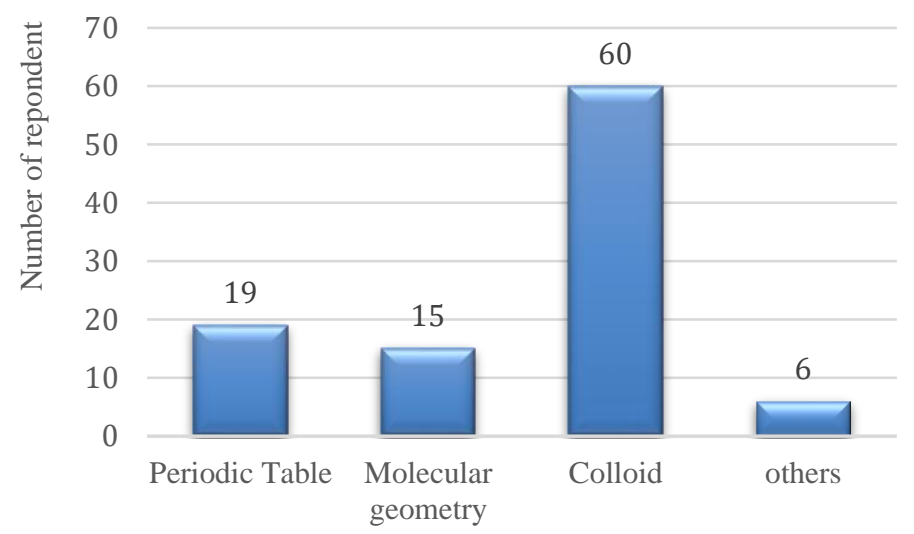

Fig. 5. The chemistry concepts selected by students for game development

Fig. 4 Depicted chemistry concepts as suggested by 100 students who took part in the need analysis of the Android game. According to the graph, more than half (60 students) students preferred colloid as a selected topic of the development of an Android game. Comparing to other concepts like the periodic table of elements, and molecular geometry, the idea of colloid is somewhat confusing for students in determining the dispersion system and defining the correct example for each dispersion system. In high school, students encounter difficulties in identifying the accurate dispersion system of colloid due to phase complexity.

\subsection{Game development}

We developed the game using the Android Studio, the graphic was designed using CorelDraw $^{\mathcal{Q}}$ and the language of the content is Indonesian except for the first screen. Fig. 5 and Fig. 6 depicted some screenshots and the flowchart of the game, respectively. We prepared 40 questions to be integrated into the game, but only 30 items passed the quality assessment. Therefore, those 30 questions were employed as contents of the game. We intentionally switched contents between figures, texts, and abstract figures to avoid monotonously in displaying the concept of colloids, and we also focused on including only the following sub-concepts: the dispersion of colloids, examples, type of colloids, and colloidal properties like Brown motion, Tyndall effect, Electrophoresis and coagulation of colloids. 

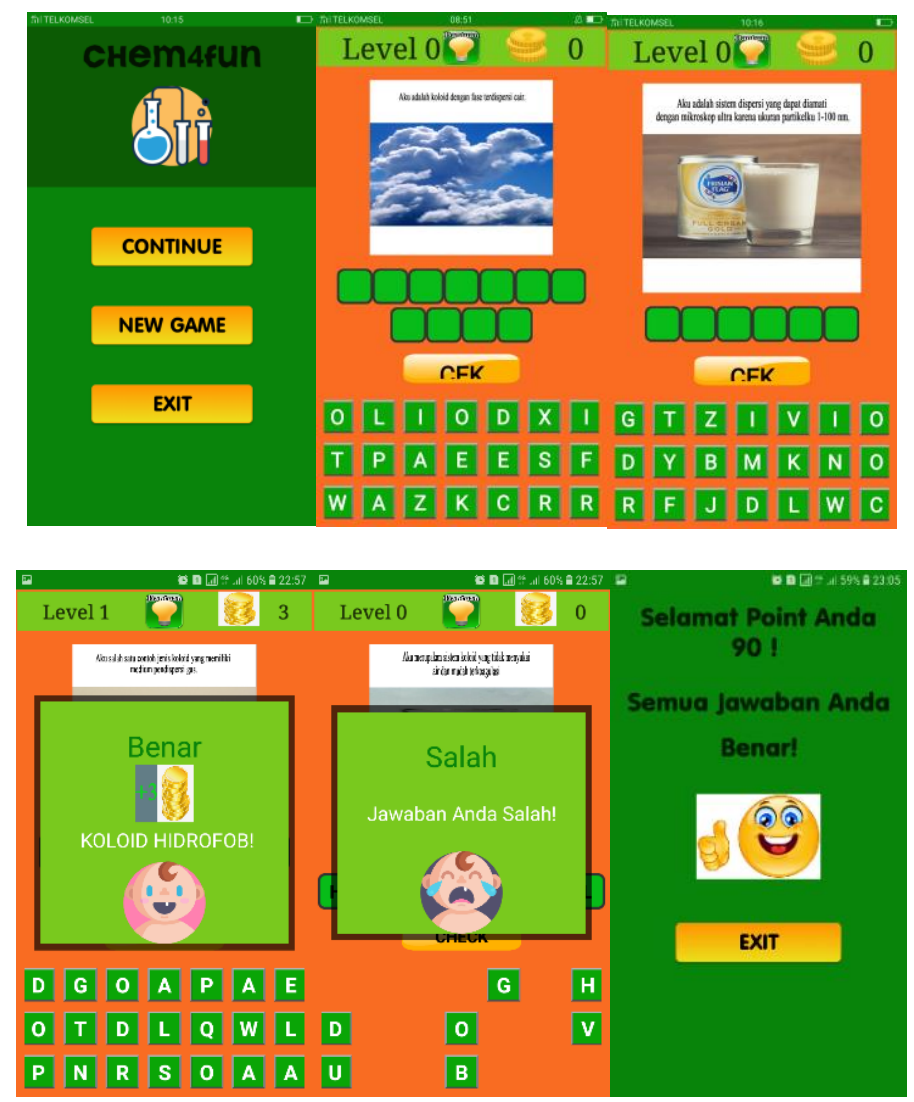

Fig. 6. Screenshots of the game 


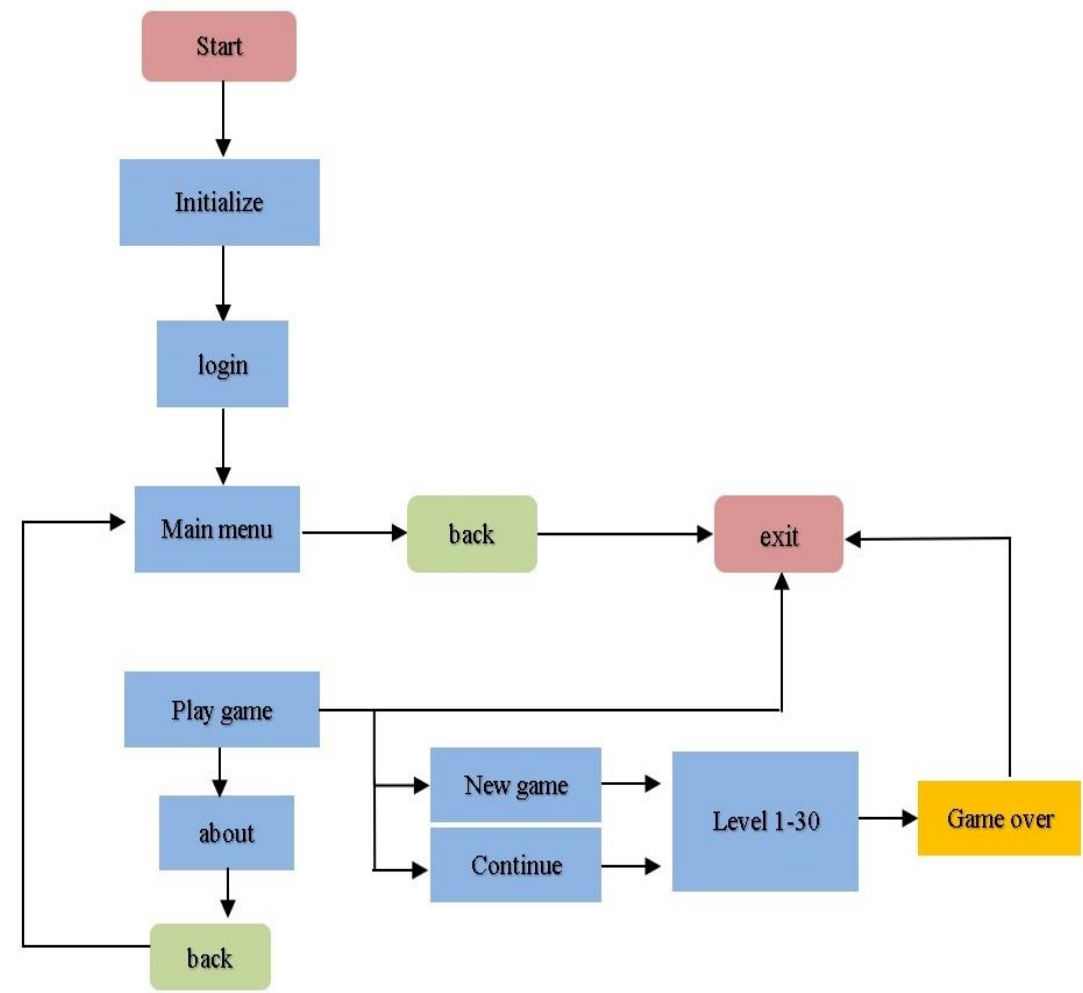

Fig. 7. The flowchart of the app

\subsection{Media and content validity}

The content and media validity assessment was conducted twice to ensure the correctness of contents inserted in the game. Furthermore, the questions also have been tested in a small group of students before the implementation; the test was necessarily conducted to evaluate whether the items are understandable, answerable, and properly designed. Content validity is a crucial aspect in quantitative educational research [32], which determines the correctness of content knowledge, as well as its coherency with the questions, appeared in the quiz [33].

Fig.8 shows that the software design was excellent, with a score of 99 out of 100 . The graph also depicted an insignificant validity decline for both visual, communication, and educational design aspects of the app. In short, overall scores of validity indicated that the app was ready to be used in the implementation phase. 


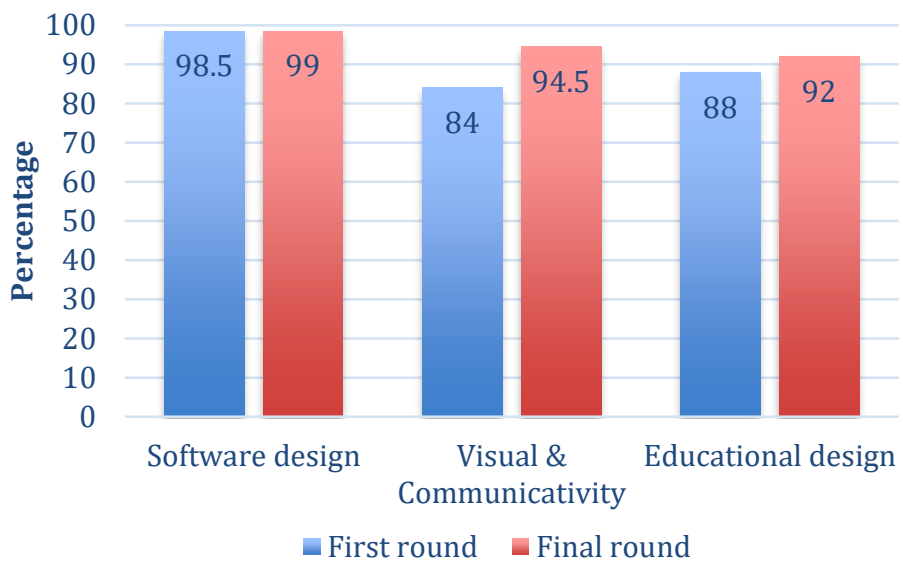

Fig. 8. Validity Scores of the App

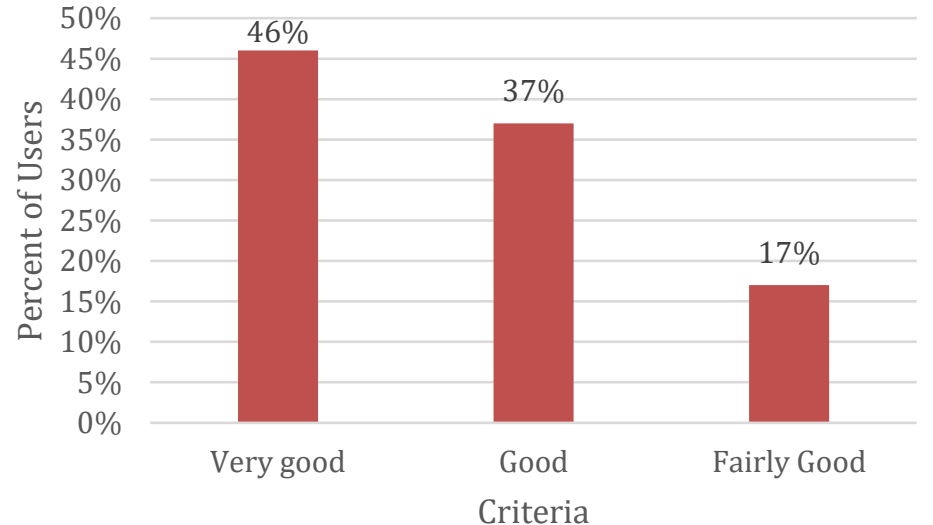

Fig. 9. System Usability Scores Given by 100 students

Fig.9 shows that almost a half of the students (46\%) found that the app is straightforward to use as learning tools, and the total score of usability was $85.1 \%$, which is marked as an excellent criterion. Usability of mobile app is a qualitative criterion that applies not only to the user interface of a product, but also to its functionality and specific context of the app use [34]. Based on the results, we strongly suggest educators engage students in the proper smartphone application to encourage them to learn independently and fast. Although some educators argued that smartphone use might cause a negative impact on students' academic performance [35]-[37], other researchers who successfully implemented the ICT integration to the classroom find the opposite results, Kaur et al. [38] argued that even there is a negative implication of smartphone use on students' performance at schools, smartphones controlled use can provide a positive contribution to student's ICT literacy. Not only because the smartphone is handy and 
easy to operate, but in the digital era, smartphones have also been an excellent replacement for computers or laptops in terms of practicality and mobility. Learning through smartphone screens is much more interesting for young people nowadays[39] comparing to books, laptop computers, or any other resources available.

\section{Conclusion}

Although the smartphone has been responsible for students' academic performance decline all over the world, we believe that controlling the smartphone use with a proper app like a specific subject matter game could encourage students to learn better and independently. In this paper, we show that the particular app designed for the chemistry concept of colloids could attract students to learn chemistry, which indicated by the usability scores of the app, students' interest, and demand of the game (see need analysis).

\section{Acknowledgement}

This work was supported by Universitas Syiah Kuala with the contract number: 106/UN11.2.1/PT.01.03/PNBP/2020.

\section{$6 \quad$ References}

[1] Manjale, N.B and Abel, C. Significance and Adequacy of Instructional Media as Perceived by Primary School Pupils and Teachers in Kinondoni District, Tanzania. International Journal of Educational Policy Research and Review. vol. 4, no. 6, pp. 151-157, 2017. https://doi.org/10.15739/IJEPRR.17.016\%20

[2] Meenakshi. Importance of ICT in Education. Journal of Research and Method in Education. vol. 1, no. 4, pp. 3-8, 2013.

[3] S and Rosdy, W.A.W. Teaching and Learning with Technology: Effectiveness of ICT Integration in Schools. International Journal of Research in Education and Science. vol. 1, no. 2, p. 175, 2015. https://doi.org/10.21890/ijres.23596

[4] Salameh, B, Ewais, A, and Salameh, O. Integrating M-Learning in Teaching ECG Reading and Arrhythmia Management for Undergraduate Nursing Students. International Journal of Interactive Mobile Technology. vol. 14, no. 01, p. 82, 2020. https://doi.org/10. $\underline{3991 / i j i m . v 14 i 01.11417}$

[5] Ministry of Education and Culture. The Statistics of General Senior Secondary School Year 2016/2017. Jakarta, 2017.

[6] Nihuka, K.A, and Peter, F. Challenges Facing Implementation of ICT Curriculum in Primary Schools. in Inaugural International conference on Open and Flexible Education. 2014, no. January, pp. 1-20.

[7] Soewarno, Hasmiana, Faiza. Kendala-Kendala Yang Dihadapi Guru Dalam Memanfaatkan Media Berbasis Komputer Di SD Negeri 10 Banda Aceh. Jurnal Pesona Dasar, vol. 2, no. 4, pp. 28-39, 2017. https://doi.org/10.24815/pear.v6i1.10705 
[8] Machmud, K. The Smartphone Use in Indonesian Schools: The High School Students' Perspectives. Journal of Arts and Humanities. vol. 7, no. 3, p. 33, 2018. https://doi.org/10. 18533/journal.v7i3.1354

[9] El-sofany, H.F, and El-haggar, N. The Effectiveness of Using Mobile Learning Techniques to Improve Learning Outcomes in Higher Education. International Journal of Interative Mobile Technologies. vol. 14, no. 8, pp. 4-18, 2020. https://doi.org/10.3991/ijim.v14i08. $\underline{13125}$

[10] Santoso A, and Lestari, S. The Roles of Technology Literacy and Technology Integration to Improve Students' Teaching Competencies. in 3rd ICEEBA International Conference on Economics, Education, Business and Accounting, 2019, vol. 3, no. 11, p. 243. https://doi.org/10.18502/kss.v3i11.4010

[11] Luke, B and Hogarth, K. Developing and Enhancing Independent Learning Skills Using Video Tutorials as A Means of Helping Students Help Themselves. Accounting Research Journal. vol. 24, no. 3, pp. 290-310, 2011. https://doi.org/10.1108/10309611111 $\underline{187019}$

[12] Matos, J.F, Pedro, A, and Piedade, J. Integrating Digital Technology in the School Curriculum. International Journal of Emerging Technology in Learning. vol. 14, no. 21, pp. 4-15, 2019. https://doi.org/10.3991/ijet.v14i21.10863

[13] Cahyana, U, Paristiowati, M, Savitri, D.A, and Hasyrin, S.N. Developing and Application of Mobile Game-Based Learning (M-GBL) for High School Students Performance in Chemistry. Eurasia Journal of Mathematics, Science and Technology Education. vol. 13, no. 10, pp. 7037-7047, 2017. https://doi.org/10.12973/ejmste/78728

[14] Haßler, B, Major, L and Hennessy, S. Tablet Use in Schools: A Critical Review of the Evidence for Learning Outcomes. Journal of Computer Assisted Learning. vol. 32, no. 2, pp. 139-156, 2016. https://doi.org/10.1111/jcal.12123

[15] Liu, T.C, Lin, Y.C and Paas, F. Effects of Cues and Real Objects on Learning in a Mobile Device Supported Environment. British Journal of Educational Technology. vol. 44, no. 3, pp. 386-399, 2013. https://doi.org/10.1111/j.1467-8535.2012.01331.x

[16] Liu, T.C, Lin, Y.C, and Paas, F. Effects of Prior Knowledge on Learning from Different Compositions of Representations in a Mobile Learning Environment. Computers and Education. vol. 72, pp. 328-338, 2014. https://doi.org/10.1016/j.compedu.2013.10. $\underline{019}$

[17] Goodwin, K. Use of Tablet Technology in the Classroom. Sydney, 2012.

[18] Sannikov, S, Zhdanov, F, Chebotarev, P, and Rabinovich, P. Interactive Educational Content Based on Augmented Reality and 3D Visualization. in Procedia - Procedia Computer Science, 2015, vol. 66, pp. 720-729. https://doi.org/10.1016/j.procs.2015.11.082

[19] Alomari, I, Al-Samarraie, H, and Yousef, R. The Role of Gamification Techniques in Promoting Student Learning:A Review and Synthesis. Journal of Information Technology Education. vol. 18, pp. 142-161, 2019.https://doi.org/10.28945/4417.

[20] Galustyan, O.V, Petelina, E.A, and Ryzhenkov, A.Y. Application of Educational Games for Formation and Development of ICT Competence of Teachers. International Journal of Emerging Technologies in Learning., vol. 14, no. 15, pp. 193-201, 2019. https://doi.org/10.3991/ijet.v14i15.10572

[21] Zielinski, D. Can Playing Games Help Students Master Concepts from General Psychology Classes?. International Journal of Game-Based Learning. vol. 9, no. 2, pp. 55-72, 2019. https://doi.org/10.4018/ijgbl.2019040104

[22] Noemí, P.M, and Máximo, S.H. Educational Games for Learning. Universal Journal of Educational Research. vol. 2, no. 3, pp. 230-238, 2014. https://doi.org/10.13189/ ujer.2014.020305 
[23] Sari, S, Anjani, R, Farida, I and Ramdhani M.A. Using Android-Based Educational Game for Learning Colloid Material. Journal of Physics:Conference Series. vol. 895, no. 1, 2017. https://doi.org/10.1088/1742-6596/895/1/012012

[24] Winarti, A, Tirto, F. R, Aprilia, A. D., Raihana, E, and Hidayati, N. The Development of Chemtective Game-Based Medium on Chemistry Learning. in 5th South East Asia Development Research (SEA-DR) International Conference The, 2017, vol. 100, pp. 18-21. https://doi.org/10.2991/seadric-17.2017.5

[25] Wardani, S, Lindawati, L, and Kusuma, S. B. W. The development of Inquiry by Using Android-system-based Chemistry Board Game to Improve Learning Outcome and Critical Thinking Ability. Jurnal Pendidikan IPA Indonesia. vol. 6, no. 2, pp. 196-205, 2017. https://doi.org/10.15294/jpii.v6i2.8360

[26] Alhashimi, S., Al Muwali, A., Zaki, Y., and Mahdi, N. The Effectiveness of Social Media and Multimedia-Based Pedagogy in Enhancing Creativity among Art, Design , and Digital Media Students. International Journal of Emerging Technologies in Learning. vol. 14, no. 21, pp. 176-190, 2019. https://doi.org/10.3991/ijet.v14i21.10596

[27] Nazar M., et al., "Development of Augmented Reality Application for Learning the Concept of Molecular Geometry," Journal of Physics: Conference Series. vol. 1460, p. 012083, 2020. https://doi.org/10.1088/1742-6596/1460/1/012083

[28] Brooke, J. SUS - A quick and dirty usability scale. pp. 189-194, 1996.

[29] Callan A., and Kortum, P. The Relationship between Task-level and Test-level System Usability Scale Scores. Proceedings of the Human Factors and Ergonomic Society. vol. 2014Janua, pp. 1139-1143, 2014. https://doi.org/10.1177/1541931214581238

[30] Nazar, M., Muliana, R., and Hanum, L. Smartphone Use and its Effects on the Student Final Grade (a case study in the Environmental Chemistry Class), in Proceeding of the 2nd URICES, 2018, pp. 978-979.

[31] Agoro, S., Sopandi, W., and Solehuddin, M. Influence of Joyful Learning on Elementary School Students'Attitudes Toward Sciences," in Journal of Physics: Conference Series, 2017, no. 812. https://doi.org/10.1088/1742-6596/812/1/012001

[32] Masuwai, A., Tajudin, N. M., and Saad, N. S. Evaluating the Face and Content Validity of a Teaching and Learning Guiding Principles Instrument (TLGPI): A Perspective Study of Malaysian Teacher Educators. Geografia - Malaysian Journal of Society and Space. vol. 12, no. 3, 2016. https://doi.org/10.1063/1.4983911

[33] Bujeng, B., Kamis, A., Hussain, M.A.M., Rahim, M.B., and Soenarto, S. Validity and Reliability of Multimedia Interactive Making Clothes (MIMP) Module for Home Science Subjects. International Journal of Innovative Technology and Exploring Engineering. vol. 8, no. 8 S, pp. 593-596, 2019.

[34] Nacheva, R.V. Standardization Issues of Mobile Usability. International Journal of Interactive Mobile Technology. vol. 14, no. 07, p. 149, 2020. https://doi.org/10.3991/ ijim.v14i07.12129

[35] Ng, S.F., Hassan, N.S.I.C., Nor, N.H.M., and Malek, N.A.A. The Relationship Between Smartphone Use and Academic Performance: A Case of Students in a Malaysian Tertiary Institution. Malaysia Online Journal of Educational Techology. vol. 5, no. 4, pp. 56-73, 2017.

[36] Amez, S., and Baert, S. Smartphone Use and Academic Performance : A Literature Review Smartphone Use and Academic Performance : A Literature Review. Discussion Paper Series. vol. October, no. 12723, 2019. https://doi.org/10.1016/j.ijer.2020.101618

[37] Baert, S. et al. Smartphone Use and Academic Performance: Correlation or Causal Relationship?. KYKLOS, vol. 73, no. 1, pp. 1-25, 2019. https://doi.org/10.1111/kykl.12214 
[38] Singh, M.K.K., and Samah, N.A. Impact of Smartphone: A Review on Positive and Negative Effects on Students. Asian Social Science. vol. 14, no. 11, p. 83, 2018.https://doi.org/ 10.5539/ass.v14n11p83

[39] Hossain, S.F.A., Nurunnabi, M., Hussain, K., and Saha, S.K. Effects of Variety-seeking Intention by Mobile Phone Usage on University Students' Academic Performance. Cogent Education. vol. 6, no. 1, pp. 1-18, 2019. https://doi.org/10.1080/2331186x.2019. $\underline{1574692}$

\section{$7 \quad$ Authors}

Muhammad Nazar is a member of the Association of Indonesian Science Educators, a senior lecturer at the department of chemical education, Faculty of Education and Teacher Training, Universitas Syiah Kuala. He is interested in the research of Android development, learning media, chemistry, and biodiesel. Email: mnazar@unsyiah.ac.id

Rusman is an associate professor at the Department of Chemical Education, Faculty of Education and Teacher Training, Universitas Syiah Kuala.

Isfin Cahyani Putri is an undergraduate student at the department of chemical education, Faculty of Education and Teacher Training, Universitas Syiah Kuala.

Kana Puspita is a junior lecturer at the Department of Chemistry Education, Faculty of Education and Teacher Training, Universitas Syiah Kuala.

Article submitted 2020-03-23. Resubmitted 2020-06-09. Final acceptance 2020-06-08. Final version published as submitted by the authors. 